\title{
Phylogenetic taxon definitions for Fungi, Dikarya, Ascomycota and Basidiomycota
}

\author{
David S. Hibbett ${ }^{1}$, Meredith Blackwell ${ }^{2}$, Timothy Y. James ${ }^{3}$, Joseph W. Spatafora ${ }^{4}$, John W. Taylor ${ }^{5}$, and Rytas Vilgalys ${ }^{6}$
}

1Biology Department, Clark University, Worcester, MA 01610, USA; corresponding author e-mail: dhibbett@clarku.edu

${ }^{2}$ Department of Biology, Louisiana State University, Baton Rouge, LA 70803 and Department of Biological Sciences, University of South Carolina, Columbia, SC 29208, USA

${ }^{3}$ Department of Ecology and Evolutionary Biology, University of Michigan, Ann Arbor, MI 48109, USA

${ }^{4}$ Department of Botany and Plant Pathology, Oregon State University, Corvallis, OR 97331, USA

${ }^{5}$ Department of Plant and Microbial Biology, University of California, Berkeley, CA 94720, USA

${ }^{6}$ Biology Department, Duke University, Durham NC 27708, USA

Abstract: Phylogenetic taxon definitions (PTDs) are explicit, phylogeny-based statements that specify clades. PTDs are central to the system of rank-free classification that is governed by the PhyloCode, but they can also

Key words: classification PhyloCode rank-free taxonomy systematics

Article info: Submitted: 11 June 2018; Accepted: 11 September 2018; Published: 12 September 2018.

\section{INTRODUCTION}

Phylogenetic taxon definitions (PTDs) are explicit, phylogenybased statements that are used to describe clades in the rank-free approach to classification known as "phylogenetic taxonomy" (De Queiroz \& Gauthier 1992). The principles and nomenclatural rules of phylogenetic taxonomy are described in the International Code of Phylogenetic Nomenclature (the PhyloCode), which is available on-line (https://www.ohio. edu/phylocode/) but is not yet published. The PhyloCode has encountered strident opposition (see the website for a comprehensive review of literature, both pro and con), but PTDs are not synonymous with the PhyloCode - they are simply devices for identifying clades with reference to phylogenies. PTDs can be used to describe ranked or unranked taxa. They can also be translated into Least Common Ancestor algorithms, which facilitate automated taxonomic data retrieval from phylogenies (Hibbett et al. 2005). Here, we present PTDs for four taxa that have been described in accordance with the Code (Turland et al. 2018): Fungi, Dikarya, Ascomycota, and Basidiomycota. The compositions of these clades, as defined here, are consistent with (most) current usage.

More than a decade has passed since the "AFTOL classification" momentarily unified the higher-level taxonomy of Fungi (Hibbett et al. 2007). Since then, mycology has witnessed the advent of phylogenomics and the recognition of groups such as Cryptomycota, Entorrhizomycota, Mucoromycota, and Opisthosporidia, among others (Bauer et al. 2015, Jones et al. 2011, Karpov et al. 2014, Spatafora et al. 2016). However, there is still uncertainty about the higher-level placements of many clades, particularly those for which there are as yet no genomes available (like Entorrhizomycota), which can destabilize classifications. There are also disagreements about the rankings of names that correspond to wellestablished monophyletic groups, such as Glomeromycota/ Glomeromycotina (Spatafora et al. 2016, Tedersoo et al. 2018). Even the delimitation of Fungi is controversial (Berbee et al. 2017, James et al. 2006, Karpov et al. 2014).

It is in the interests of the user community for fungal systematists to converge on a uniform set of names for well-supported clades. As genome sampling expands, many problematical nodes in the fungal phylogeny will be resolved, but improvements in phylogenetic resolution do not automatically translate into taxonomy. PTDs could promote taxonomic clarity and stability, by providing clear guidelines for representing phylogenetic trees in classifications based solely on tree topology, not arbitrary considerations, like phenotypic distinctiveness, or estimates of quantities with broad confidence intervals, such as taxonomic richness or ages of clades.

PTDs can take several forms. The PTDs for Fungi and Dikarya (below) are node-based definitions (also called minimum-crown-clade definitions), which consist of statements like "Taxon $\mathrm{X}$ is the least inclusive clade containing species A and species B", while the PTDs for Ascomycota and Basidiomycota are stem-based definitions (also called maximum-crown-clade definitions), which take the form "the largest group containing species A but not species B". In both kinds of definitions, species $A$ and species $B$ serve as "specifiers" (Fig. 1).

\section{๑) 2018 International Mycological Association}

You are free to share - to copy, distribute and transmit the work, under the following conditions:

Attribution: $\quad$ You must attribute the work in the manner specified by the author or licensor (but not in any way that suggests that they endorse you or your use of the work).

Non-commercial: $\quad$ You may not use this work for commercial purposes.

No derivative works: You may not alter, transform, or build upon this work.

For any reuse or distribution, you must make clear to others the license terms of this work, which can be found at http://creativecommons.org/licenses/by-nc-nd/3.0/legalcode. Any of the above conditions can be waived if you get permission from the copyright holder. Nothing in this license impairs or restricts the author's moral rights. 

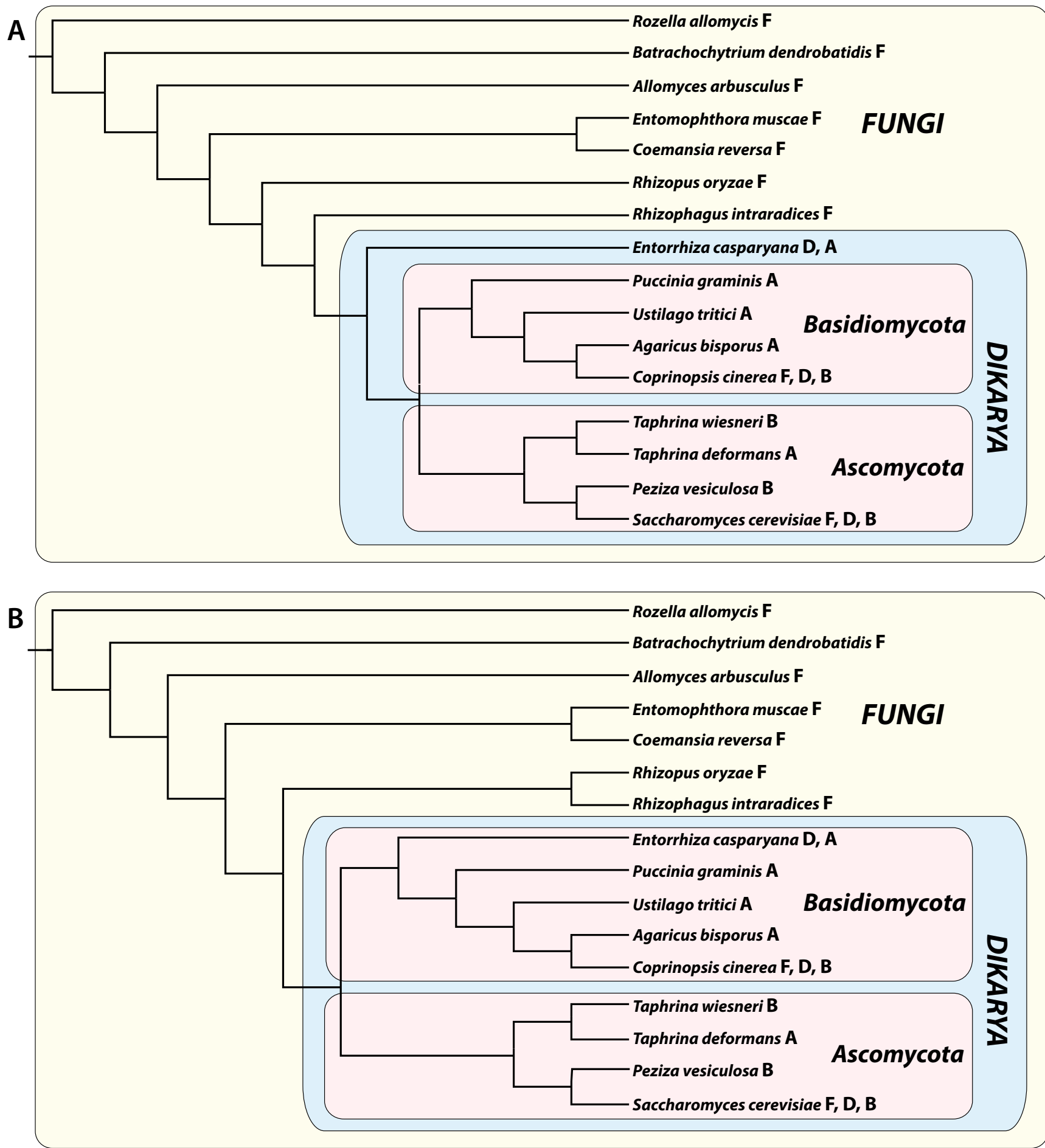

Fig. 1. Phylogenetic taxon definitions and specifiers for Fungi, Dikarya, Ascomycota and Basidiomycota. Capital letters following species names indicate the clade(s) for which they serve as specifiers ( $F$ for Fungi, and so on). There are two species of Taphrina in the tree: $T$. wiesneri, which was included in the reference phylogeny for Basidiomycota, and T. neoformans, which was used in the reference phylogeny for Ascomycota. A. Topology based on James et al. (2006: fig. 1) and Bauer et al. (2015: fig. 2). B. Topology based on Spatafora et al. (2016: fig. 1) and the alternative topology of Bauer et al. (2015), which was described but not illustrated.

Carefully crafted PTDs can accommodate phylogenetic uncertainty. For example, the node-based PTD of Fungi includes Rozella allomycis as a specifier, because its position in the sister group to the rest of Fungi is strongly supported by genome data (James et al. 2013), but it does not use aphelids, because there are no genomes yet available, or microsporidia because their placements are likely to remain controversial due to their high rates of molecular evolution (see the Comments for Fungi, below). Similarly, the stembased PTD of Basidiomycota does not use a species of Entorrhizomycota as a specifier; Entorrhizomycota has been resolved as either (1) the sister group of Dikarya, or (2) more closely related to Pucciniomycotina, Ustilaginomycotina, and Agaricomycotina than to Ascomycota (Bauer et al. 2015). 
Entorrhiza casparyana is a specifier in the node-based PTD for Dikarya, which ensures that Entorrhizomycota is retained in Dikarya, under either of the topologies reported by Bauer et al. (2015) (Fig. 1).

The history of phylogenetic taxonomy is long and torturous. As reviewed in the Preface to the PhyloCode, the concept of phylogeny-based, rank-free classification had its origins in theoretical discussions of the 1980s, and a formal code began to take shape in the late 1990s. In 2002, a decision was made to tie the publication of the PhyloCode to a "Companion Volume" that would present PTDs for clades across the entire tree of life (or at least eukaryotes). Delays in preparation of the Companion Volume have forestalled publication of the PhyloCode, but the project may be nearing completion. The PTDs and associated text presented here were first submitted for the Companion Volume in 2008, and revised and resubmitted in 2017. We anticipate that they will appear in the Companion Volume essentially in the form below, except that the references will be formatted differently, each name will be identified as a "converted clade name", and each entry will include an abbreviated form of the definition and a registration number.

Whether or not mycologists choose to publish names that follow the rules of the PhyloCode, PTDs have the potential to help resolve taxonomic disputes and focus attention on tree topology. PTDs have not been widely adopted by mycologists, although they are used for some taxa (including Dikarya) in the classification of protists and other eukaryotes by Adl et al. (2012). It is hoped that the PTDs presented below will clarify and stabilize application of the names Fungi, Dikarya, Ascomycota, and Basidiomycota, and provide a model for other mycologists who wish to name clades, ranked or otherwise.

The authors of the entries for each of the higher taxon names treated here are indicated at the end of each entry.

\section{TAXONOMY}

\section{Fungi R.T. Moore, Bot. Marina 23: 371 (1980).}

Definition: The smallest crown clade containing Rozella allomycis F.K. Faust 1937, Batrachochytrium dendrobatidis Longcore et al. 1999, Allomyces arbusculus E.J. Butler 1911, Entomophthora muscae (Cohn) Fresen.1856, Coemansia reversa Tiegh. \& G. Le Monn. 1873, Rhizophagus intraradices (N.C. Schenck \& G.S. Sm.) C. Walker \& A. Schüßler 2010, Rhizopus oryzae Went \& Prins. Geerl. 1895, Saccharomyces cerevisiae Meyen 1838, and Coprinopsis cinerea (Schaeff.) Redhead et al. 2001. This is a minimum-crown-clade definition.

Etymology: Derived from the Latin fungus (mushroom).

Reference phylogeny: The primary reference phylogeny is James et al. (2006: fig. 1). See also James et al. (2013: fig. 2), Karpov et al. (2013: fig. 3), Paps et al. (2013: fig. 1), Chang et al. (2015: fig. 1), Torruella et al. (2015: fig. 1), and Spatafora et al. (2016: fig. 1).
Composition: Rozella, Microsporidia, Aphelida, Chytridiomycota, Neocallimastigomycota, Blastocladiomycota, Mucoromycota, Zoopagomycota, Ascomycota and Basidiomycota (Hibbett et al. 2007, Karpov et al. 2014, Spatafora et al. 2016).

Diagnostic apomorphies: There are no unambiguous morphological, subcellular, or biochemical synapomorphies of Fungi. Most Fungi are filamentous, have chitinous cell walls, lack flagella, and have intranuclear mitosis with spindle pole bodies (instead of centrioles). However, there are also numerous unicellular forms (yeasts) scattered across the fungal phylogeny, thalli without hyphal growth developing from spores by cell division (Laboulbeniomycetes), and forms that develop centrioles and produce flagellated cells that lack cell walls during the motile part of their life cycles (the paraphyletic "chytrids": Chytridiomycota, Neocallimastigomycota, Blastocladiomycota, and Rozella allomycis). Rozella, Microsporidia and Aphelida are intracellular parasites of diverse eukaryotes. Rozella and Aphelida produce both zoosporic stages and endoparasitic amoeboid forms that appear to ingest cytoplasm of their hosts by phagocytosis, whereas Microsporidia lack a phagotrophic stage and infect hosts by a polar tube mechanism (Corsaro et al. 2014, James \& Berbee 2012, Karpov et al. 2014, Powell et al. 2017). Rozella allomycis may also employ enzymatic degradation to penetrate the host cell wall (Held 1972). The $R$. allomycis genome encodes four division II chitin synthase genes, which are characteristic of other Fungi, including Microsporidia (James et al. 2013). However, division II chitin synthase genes have also been found in the holozoan protists (Teretosporea), diatoms, and Metazoa, suggesting that they may be plesiomorphic in Opisthokonta (Torruella et al. 2015).

\section{Synonym: Eumycota sensu Barr (1992) [approximate].}

Comments: Application of the name Fungi to this clade, and the choice of this name rather than its approximate synonym Eumycota follows the phylogeny-based classification of Hibbett et al. (2007), which has been adopted in all editions of Ainsworth \& Bisby's Dictionary of the Fungi since 1971 (Ainsworth et al. 1971, Kirk et al. 2008) and the GenBank taxonomy (http://www.ncbi.nlm.nih.gov/guide/taxonomy). The delimitation of Fungi by Hibbett et al. (2007) was based largely on the phylogenetic analysis of James et al. (2006), which used six genes and recovered a clade containing $R$. allomycis and Microsporidia as the sister group of all other Fungi. Earlier analyses using $\alpha$-tubulin and $\beta$-tubulin genes also placed Microsporidia within Fungi (Edlind et al. 1996, Keeling 2003, Keeling \& Doolittle 1996). Recent studies using data derived from whole genomes or transcriptomes have consistently supported monophyly of the clade containing Rozella plus Microsporidia and have placed it as the sister group to the remaining Fungi (James et al. 2013, Ren et al. 2016, Torruella et al. 2015)

Several studies, including combined analyses of genes encoding ribosomal RNA (rRNA) and RNA polymerase II ( $r p b 1$ and $r p b 2$ ), have suggested that the clade containing Rozella and Microsporidia also contains the endoparasitic Aphelida (Corsaro et al. 2014, Karpov et al. 2013, Letcher et al. 2015), collectively termed the "ARM clade" (Karpov et al. 2014). 
However, other analyses using rRNA genes only have placed Aphelida as the sister group of a clade containing Rozella, Microsporidia, and all other Fungi (Corsaro et al. 2016). The minimum-crown-clade definition of Fungi proposed here employs multiple specifiers, but $R$. allomycis is the only specifier in the ARM clade. Microsporidia were not used as specifiers, because they have a dramatically elevated rate of molecular evolution (Corradi 2015), and Aphelida were not used, because they are still represented only by a handful of genes. Nevertheless, current best estimates of the phylogeny suggest that Microsporidia and Aphelida are members of Fungi as defined here.

The sister group of Fungi (including Aphelida) appears to be a clade containing nucleariids and Fonticula alba (Brown et al. 2009, Paps et al. 2013, Torruella et al. 2015). The former are phagotrophic, non-flagellated, amoeboid protists that lack a cell wall, and the latter is a kind of cellular slime mold with aggregative, multicelluar reproductive structures that produces spores with cell walls lacking chitin. Berbee et al. (2017) suggested that the nucleariid- $F$. alba clade should be included in Fungi. However, most studies refer to the group containing Fungi and the nucleariid- $F$. alba clade as Holomycota (Corsaro et al. 2014, Karpov et al. 2014, Liu et al. 2009, Paps et al. 2013, Torruella et al. 2015), or, less often, Nucletmycea (Adl et al. 2012, Brown et al. 2009).

Karpov et al. (2014) named the ARM clade Opisthosporidia and suggested that it should be excluded from Fungi. However, Rozella has traditionally been considered a fungus based on morphological and ecological similarities to other chytrids, and Microsporidia have been widely regarded as members of Fungi ever since the early analyses using tubulin genes (Edlind et al. 1996, Keeling \& Doolittle, 1996). Thus, the present definition preserves the composition of Fungi as it has come to be understood since the mid-1990s (e.g. Hibbett et al. 2007, James et al. 2006, Kirk et al. 2008, Spatafora et al. 2017), with the likely addition of Aphelida and other recently discovered members of the ARM clade (Jones et al. 2011). Moreover, evidence from comparative genomics and ultrastructural studies supports the view that members of the ARM clade are highly reduced and that their common ancestor may have been free-living and possessed many traits typically associated with Fungi, including chitinous cell walls and possibly osmoheterotrophy (Berbee et al. 2017, Held 1972, James et al. 2013, Keeling \& Corradi 2011, Quandt et al. 2017).

D. S. Hibbett, M. Blackwell, T. Y. James, J. W. Spatafora, J. W. Taylor, and R. Vilgalys

Dikarya D. S. Hibbett et al., Mycol. Res. 111: 518 (2007).

Definition: The smallest crown clade containing Coprinopsis cinerea (Schaeff.) Redhead et al. 2001 (Basidiomycota), Saccharomyces cerevisiae Meyen 1838 (Ascomycota), and Entorrhiza casparyana (Magnus) Lagerb. 1888 (Entorrhizomycota). This is a minimum-crown-clade definition.

Etymology: Derived from the Greek di- (two) and karyon (nut or kernel, interpreted by biologists to refer to nuclei).
Reference phylogeny: The primary reference phylogeny is Bauer et al. (2015: fig. 2). See also James et al. (2006: fig. 1), Ebersberger et al. (2011: fig. 3), Chang et al. (2015: fig. 1), and Ren et al. (2016: fig. 5).

Composition: Ascomycota and Basidiomycota, including Entorrhizomycetes (Hibbett et al. 2007).

Diagnostic apomorphies: The dikaryotic condition, which results from cytoplasmic fusion of two haploid, monokaryotic hyphae, is the putative synapomorphy for which the group is named. Clamp connections of Basidiomycota and croziers of Ascomycota, which are cellular structures that function in the apportioning of nuclei to daughter cells following mitosis in dikaryotic hyphae, may be homologous and could represent an additional synapomorphy. Regularly septate hyphae are also probably a synapomorphy, because members of the candidate sister taxon, Mucoromycota (Spatafora et al. 2016, 2017), have predominantly coenocytic hyphae (Benny et al. 2014, Hibbett et al. 2007, Redecker \& Schüßler 2014). If clamps/croziers and septate hyphae of Basidiomycota and Ascomycota are homologous, then the ancestor of Dikarya must have been filamentous, and the unicellular forms (yeasts) that occur in multiple major clades of both Ascomycota and Basidiomycota were derived by reduction (Nagy et al. 2014).

Synonyms: Carpomyceteae Bessey 1907 [approximate], Dikaryomycota W. B. Kendr. 1985 [approximate], Neomycota Caval.-Sm. 1998 [approximate].

Comments: Application of the name Dikarya to this clade, and the choice of this name rather than one of the infrequently used synonyms Dikaryomycota and Neomycota, follow the phylogeny-based classification of Hibbett et al. (2007), which has been adopted in Ainsworth \& Bisby's Dictionary of the Fungi (Kirk et al. 2008) and the GenBank taxonomy (http:// www.ncbi.nlm.nih.gov/guide/taxonomy). James et al. (2006) used the name Dikarya in the same sense as that proposed here, but the name was first validly published (according to the ICN; Turland et al. 2018) by Hibbett et al. (2007). Monophyly of Dikarya is strongly supported by independent and combined analyses of nuclear ribosomal RNA genes, RNA polymerase II subunits, and whole genomes (Chang et al. 2015, James et al. 2006, Ren et al. 2016). The position of Entorrhizomycetes within Dikarya is not well resolved (see Comments under Basidiomycota).

\section{S. Hibbett, M. Blackwell, T. James, J. W. Spatafora, J.} W. Taylor, and R. Vilgalys

\section{Ascomycota Caval.-Sm., Biol. Rev. 73: 247 (1998).}

Definition: The largest crown clade containing Taphrina deformans (Berk.) Tul. 1866, but not Puccinia graminis Pers. 1794, Ustilago tritici (Bjerk.) Rostr. 1890, Agaricus bisporus (J.E. Lange) Imbach 1946, and Entorrhiza casparyana (Magnus) Lagerb. 1888. This is a maximum-crown-clade based definition. 
Etymology: Derived from the Greek askos (sac) + mykes (fungus).

Reference phylogeny: The primary reference phylogeny is Bauer et al. (2015: fig. 2). See also Lutzoni et al. (2004: fig. 2), Liu et al. (2008: fig. 1), James et al. (2006: fig. 1), Schoch et al. (2009: fig. S6), Carbone et al. (2017: fig. 1), and Spatafora et al. (2017: fig. 1).

Composition: Taphrinomycotina, Saccharomycotina and Pezizomycotina (Hibbett et al. 2007).

Diagnostic apomorphies: Morphological synapomorphies of Ascomycota include the formation of meiospores (ascospores) within sac-shaped meiosporangia (asci) by the process of free cell formation. Free cell formation involves the production of an enveloping membrane system, which is derived from either the ascus plasmalemma or the nuclear envelope and delimits ascospore initials. Meiotic reproduction is unknown in many species and may have been lost in some. All Ascomycota lack flagella and exhibit intranuclear mitosis with spindle pole bodies instead of centrioles (Kumar et al. 2011). Most Ascomycota are filamentous with simple septa, but there are numerous yeasts (unicellular forms) especially in the Taphrinomycotina (Healy et al. 2013) and Saccharomycotina and dimorphic species (capable of both yeast and filamentous growth) in Pezizomycotina, Taphrinomycotina and Saccharomycotina. A multicellular thallus lacking filamentous growth is formed in Laboulbeniales (Pezizomycotina) (Blackwell 1994).

Synonyms: Ascomycetes sensu Whittaker (1959) [approximate]. Ascomycotina sensu Ainsworth et al. (1971) and Ainsworth (1973) is a partial synonym because the asexual ascomycetes were excluded and assigned instead (along with other asexual fungi) to Deuteromycotina. Following extensive discussions the General Committee on Nomenclature endorsed the view that Cavalier-Smith's two-word diagnosis in Latin ("sporae intracellulares") was acceptable as a validating diagnosis and this was ratified by the 2011 International Botanical Congress (Turland et al. 2018: Art. 38 Ex. 8).

Comments: Application of the name Ascomycota to this clade, and the choice of this name rather than the synonyms Ascomycetes (class) and Ascomycotina (subphylum), follow the phylogeny-based classification of Hibbett et al. (2007), which has been adopted in Ainsworth \& Bisby's Dictionary of the Fungi (Kirk et al., 2008) and the GenBank taxonomy (http://www.ncbi.nlm.nih.gov/guide/taxonomy). In rankbased classifications (e.g. Kirk et al. 2008, Spatafora et al. 2017), the clade Ascomycota is the largest phylum of Fungi. It is supported in molecular phylogenetic analyses (Lutzoni et al. 2004, James et al. 2006, Schoch et al. 2009) and comprises three mutually exclusive subclades (Carbone et al. 2017, Schoch et al. 2009, Spatafora et al. 2006). Taphrinomycotina is sister group to a well-supported clade comprising Saccharomycotina and Pezizomycotina. Pezizomycotina includes all ascoma-producing taxa with the exception of Neolectomycetes of Taphrinomycotina. The monophyly of Taphrinomycotina was not supported by early analyses of ribosomal data (reviewed in Sugiyama et al. 2006), but sampling of protein coding loci (RPB1, RPB2, and TEF) and mitochondrial DNA in multi-gene analyses provided support for its monophyly (James et al. 2006, Liu et al. 2008, Spatafora et al. 2006). Saccharomycotina (Riley et al. 2016, Shen et al. 2016) and Pezizomycotina (Carbone et al. 2017, Kumar et al. 2012, Schoch et al. 2009, Spatafora et al. 2006) are both well-supported clades. The sister group of Ascomycota is Basidiomycota (James et al. 2006). The fossil record of Ascomycota dates to at least the Devonian, with Paleopyrenomycites (Taylor et al. 2005), and the enigmatic Prototaxites taitii (Honegger et al. 2018) identified as part of the Rhynie Chert fossil fungi, but putative ascomycete fossils have been reported from the Silurian (Sherwood-Pike \& Gray, 1985). Efforts to fit molecular phylogenies to the fossil record have estimated the origin of Ascomycota to be between 0.40 to 1.3 billion years before present (Heckman et al. 2001, Lücking et al. 2009, Taylor \& Berbee 2006).

\section{J. W. Spatafora, M. Blackwell, and J. W. Taylor}

Basidiomycota R.T. Moore, Bot. Marina 23: 371 (1980).

Definition: The largest crown clade containing Coprinopsis cinerea (Schaeff.) Redhead et al. 2001, but not Taphrina wiesneri (Ráthay) Mix 1954, Saccharomyces cerevisiae Meyen 1838, and Peziza vesiculosa Bull. 1790. This is a maximum-crown-clade definition.

Etymology: Derived from the Latin basis (base, support) plus diminutive suffix -idium, referring to the basidium, a "little pedestal", on which the basidiospores develop, plus the Greek mykes (fungus).

Reference phylogeny: The primary reference phylogeny is James et al. (2006: fig. 1). See also Bauer et al. (2015: fig. 2), Nagy et al. (2016: fig. 1), and Zhao et al. (2017: fig. 3).

Composition: Pucciniomycotina, Ustilaginomycotina, Agaricomycotina (Hibbett et al. 2007). Entorrhizomycetes may also be in Basidiomycota (Bauer et al. 2015, see Comments).

Diagnostic apomorphies: A prolonged, free-living dikaryotic mycelium and the production of meiospores on basidia are putative synapomorphies, although Basidiomycota also includes asexual taxa and unicellular forms (yeasts).

Synonyms: Basidiomycetes sensu Whittaker (1959) [approximate]. Basidiomycotina sensu Ainsworth et al. (1971) and Ainsworth (1973) is a partial synonym because the asexual basidiomycetes were excluded and assigned instead (along with other asexual fungi) to Deuteromycotina.

Comments: Application of the name Basidiomycota to this clade, and the choice of this name rather than the synonyms Basidiomycetes (class) and Basidiomycotina (subphylum), follow the phylogeny-based classification of Hibbett et al. (2007), which has been adopted in Ainsworth \& Bisby's Dictionary 
of the Fungi (Kirk et al. 2008) and the GenBank taxonomy (http://www.ncbi.nlm.nih.gov/guide/taxonomy). Monophyly of Basidiomycota has been strongly supported in phylogenetic analyses of multi-locus molecular data (James et al. 2006), including genome-based datasets (Nagy et al. 2016, Zhao et al. 2017), and was also corroborated in an analysis of nonmolecular characters (Tehler 1988). Three major subclades, Pucciniomycotina (rusts and relatives), Ustilaginomycotina (smuts and relatives), and Agaricomycotina (mushrooms, jelly fungi, and relatives), are resolved in most analyses (Aime et al. 2014, Begerow et al. 2014, Hibbett et al. 2014).

The relationship of Entorrhizomycetes to Basidiomycota is controversial (Bauer et al. 2015, Matheny et al. 2006, Zhao et al. 2017). Entorrhizomycetes includes root-gall fungi with similarities to certain Basidiomycota, including dolipore septa, dikaryotic vegetative cells, and teliospores with cruciate septation (Bauer et al. 2015). Entorrhizomycetes have been classified in Ustilaginomycotina (Begerow et al. 2006), but phylogenetic analyses of nuclear ribosomal RNA genes, alone or in combination with RNA polymerase II subunits 1 and 2 ( $r p b 1, r p b 2)$, suggest that it could be the sister group of all other Basidiomycota or of Dikarya (Bauer et al. 2015, Matheny et al. 2006, Zhao et al. 2017). Bauer et al. (2015) classified Entorrhizomycetes in its own phylum, Entorrhizomycota. There are still no whole-genome sequences available for Entorrhizomycetes.

\section{S. Hibbett, T. Y. James, and R. Vilgalys}

\section{ACKNOWLEDGEMENTS}

We are grateful to Phil Cantino for his careful editing of these taxon definitions in preparation for their publication in the PhyloCode Companion Volume, and to Paul M. Kirk and David L. Hawksworth for their helpful comments on the manuscript.

\section{REFERENCES}

Adl SM, Simpson AG, LaneCE, Lukeš J, Bass D, et al. (2012) The revised classification of eukaryotes. Journal of Eukaryotic Microbiology 59: 429-493.

Aime MC, Toome M, McLaughlin DJ (2014) Pucciniomycotina. In: The Mycota. Vol. VIIA. Systematics and Evolution (McLaughlin DJ, Spatafora JW, eds.): 271-294. $2^{\text {nd }}$ edn. Berlin: SpringerVerlag.

Ainsworth GC (1973) Introduction and keys to higher taxa. In: The Fungi: an advanced treatise (Ainsworth GC, Sparrow FK, Sussman AS, eds) 4(A): 1-7. New York: Academic Press.

Ainsworth GC, James PW, Hawksworth DL (1971) Ainsworth \& Bisby's Dictionary of the Fungi. $6^{\text {th }}$ edn. Kew: Commonwealth Mycological Institute.

Barr DJS (1992) Evolution and kingdoms of organisms from the perspective of a mycologist. Mycologia 84: 1-11.

Bauer R, Garnica S, Oberwinkler F, Riess K, Weiß M, Begerow D (2015) Entorrhizomycota: a new fungal phylum reveals new perspectives on the evolution of Fungi. PLOS One 10: e0128183.

Begerow D, Schäfer AM, Kellner R, Yurkov A, Kemler M, et al. (2014) Ustilaginomycotina. In: The Mycota. Vol. VIIA. Systematics and
Evolution (McLaughlin DJ, Spatafora JW, eds): 295-329. $2^{\text {nd }}$ edn. Berlin: Springer-Verlag.

Begerow D, M Stoll, R Bauer (2006) A phylogenetic hypothesis of Ustilaginomycotina based on multiple gene analyses and morphological data. Mycologia 98: 906-916.

Benny GL, Humber RA, Voigt K (2014) Zygomycetous fungi: phylum Entomophthoromycota and subphyla Kickxellomycotina, Mortierellomycotina, Mucoromycotina, and Zoopagomycotina. In: The Mycota. Vol. VIIA. Systematics and Evolution (McLaughlin DJ, Spatafora JW, eds): 209-250. $2^{\text {nd }}$ edn. Berlin: Springer-Verlag.

Berbee ML, James TY, Strullu-Derrien C (2017) Early-diverging fungi: diversity and impact at the dawn of terrestrial life. Annual Reviews of Microbiology 71: 41-60.

Bessey CE (1907) A synopsis of the plant phyla. University Studies, University of Nebraska 7: 275-373.

Blackwell M (1994) Minute mycological mysteries: the influence of arthropods on the lives of fungi. Mycologia 86: 1-17.

Brown MW, Spiegel FW, Silberman JD (2009) Phylogeny of the "forgotten" cellular slime mold, Fonticula alba, reveals a key evolutionary branch within Opisthokonta. Molecular Biology and Evolution 26: 2699-2709.

Carbone I, White JB, Miadlikowska J, Arnold AE, Miller MA, et al. (2017) T-BAS: Tree-Based Alignment Selector toolkit for phylogenetic-based placement, alignment downloads and metadata visualization: an example with the Pezizomycotina tree of life. Bioinformatics 33: 1160-1168.

Cavalier-Smith T (1998) A revised six-kingdom system of life. Biological Reviews 73: 203-266.

Chang Y, Wang S, Sekimoto S, Aerts AL, Choi C, et al. (2015) Phylogenomic analyses indicate that early fungi evolved digesting cell walls of algal ancestors of land plants. Genome Biology and Evolution 7: 1590-1601.

Corradi N (2015) Microsporidia: eukaryotic intracellular parasites shaped by gene loss and horizontal gene transfers. Annual Review of Microbiology 69: 167-183.

Corsaro D, Walochnik J, Venditti D, Steinmann J, Müller K-D, Michel R (2014) Microsporidia-like parasites of amoebae belong to the early fungal lineage Rozellomycota. Parasitology Research 113: 1909-1918.

Corsaro D, Michel R, Walochnik J, Venditti D, Müller K-D, et al. (2016) Molecular identification of Nucleophaga terricolae sp. nov (Rozellomycota), and new insights on the origin of the Microsporidia. Parasitology Research 115: 3003-3011.

De Queiroz K, Gauthier J (1992) Phylogenetic taxonomy. Annual Reviews of Ecology and Systematics 23: 449-480.

Ebersberger I, de Matos Simoes R, Kupczok A, Grube M, Kothe E, et al. (2011) A consistent phylogenetic backbone for the Fungi. Molecular Biology and Evolution 29: 1319-1334.

Edlind TD, Li J, Visvesvara GS, Vodkin MH, McLaughlin GL, Katiyar SK (1996) Phylogenetic analysis of $\beta$-tubulin sequences from amitochondrial protozoa. Molecular Phylogenetics and Evolution 5: 359-367.

Healy RA, Kumar TK, Hewitt DA, McLaughlin DL (2013) Functional and phylogenetic implications of septal pore ultrastructure in the ascoma of Neolecta vitellina. Mycologia 105: 802-813

Heckman DS, Geiser DM, Eidell BR, Stauffer RL, Kardos NL, Hedges SB (2001) Molecular evidence for the early colonization of land by fungi and plants. Science 293: 1129-1133.

Held AA (1972) Host-parasite relations between Allomyces and Rozella. Archiv für Mikrobiologie 82: 128-139. 
Hibbett DS, Bauer R, Binder M, Giachini AJ, Hosaka K, et al. (2014) Agaricomycotina. In: The Mycota. Vol. VIIA. Systematics and Evolution (McLaughlin DJ, Spatafora JW, eds.): 373-429. $2^{\text {nd }}$ edn. Berlin: Springer-Verlag.

Hibbett DS, Binder M, Bischoff JF, Blackwell M, Cannon PF, et al. (2007) A higher-level phylogenetic classification of the Fungi. Mycological Research 111: 509-547.

Hibbett DS, Nilsson RH, Snyder M, Fonseca M, Costanzo J, Shonfeld M (2005) Automated phylogenetic taxonomy: an example in the Homobasidiomycetes (mushroom-forming Fungi). Systematic Biology 54: 660-668.

Honegger R, Edwards D, Axe L, Strullu-Derrien CS (2018) Fertile Prototaxites taiti: a basal ascomycete with inoperculate, polysporous asci lacking croziers. Philisophical Transactions of the Royal Society of London B, 373: 20170146.

James TY, Pelin A, Bonen L, Ahrendt S, Sain D, et al. (2013) Shared signatures of parasitism and phylogenomics unite Cryptomycota and Microsporidia. Current Biology 23: 1548-1553.

James TY, Berbee ML (2012) No jacket required-new fungal lineage defies dress code. Bioessays 34: 94-102.

James TY, Kauff F, Schoch C, Matheny PB, Hofstetter V, et al. (2006) Reconstructing the early evolution of Fungi using a six-gene phylogeny. Nature 443: 818-822.

Jones MDM, Richards TA, Hawksworth DL, Bass D (2011) Validation and justification of the phylum name Cryptomycota phyl. nov. IMA Fungus 2: 173-175.

Jones MDM, Forn I, Gadelha C, Egan MJ, Bass D, et al. (2011) Discovery of novel intermediate forms redefines the fungal tree of life. Nature 474: 200-203.

Karpov SA, Mikhailov KV, Mirzaeva GS, Mirabdullaev IM, Mamkaeva $\mathrm{KA}$, et al. (2013) Obligately phagotrophic aphelids turned out to branch with the earliest-diverging Fungi. Protist 164: 195-205.

Karpov SA, Mamkaeva MA, Aleoshin VV, Nassonova E, Lilje O, Gleason FH (2014) Morphology, phylogeny, and ecology of the aphelids (Aphelidea, Opisthokonta) and proposal for the new superphylum Opisthosporidia. Frontiers in Microbiology 5: 1-11.

Keeling PJ (2003) Congruent evidence from alpha-tubulin and beta-tubulin gene phylogenies for a zygomycete origin of microsporidia. Fungal Genetics and Biology 38: 298-309.

Keeling PJ, Corradi N (2011) Shrink it or lose it: balancing loss of function with shrinking genomes in the microsporidia. Virulence 2: 67-70.

Keeling PJ, Doolittle WF (1996) Alpha-tubulin from early-diverging eukaryotic lineages and the evolution of the tubulin family. Molecular Biology and Evolution 13: 1297-1305.

Kendrick B (1985) The Fifth Kingdom. Waterloo: Mycologue Publications.

Kirk PM, Cannon PF, Minter DW, Stalpers JA (2008) Ainsworth \& Bisby's Dictionary of the Fungi. $10^{\text {th }}$ edn. Wallingford: CAB International.

Kumar TKA, Crow JA, Wennblom TJ, Abril M, Letcher PM, et al. (2011) An ontology of fungal subcellular traits. American Journal of Botany 98: 1504-1510.

Kumar TKA, Healy R, Spatafora JW, Blackwell M, McLaughlin DJ (2012) Orbilia ultrastructure, character evolution and phylogeny of Pezizomycotina. Mycologia 104: 462-476.

Letcher PM, Powell MJ, Lopez S, Lee PA, McBride RC (2015) A new isolate of Amoeboaphelidium protococcarum, and Amoeboaphelidium occidentale, a new species in phylum Aphelida (Opisthosporidia). Mycologia 107: 522-531.
Liu Y, Leigh JW, Brinkmann H, Cushion MT, Rodriguez-Ezpeleta $\mathrm{N}$, et al. (2008) Phylogenomic analyses support the monophyly of Taphrinomycotina, including Schizosaccharomyces fission yeasts. Molecular Biology and Evolution 26: 27-34.

Liu Y, Steenkamp ET, Brinkmann H, Forget L, Phillipe H, Lang BF (2009) Phylogenomic analyses predict sister group relationship of nucleariids and Fungi and paraphyly of zygomycetes with significant support. BMC Evolutionary Biology 9: 272.

Lücking R, Huhndorf S, Pfister D, Plata ER, Lumbsch H (2009) Fungi evolved right on track. Mycologia 101: 810-822.

Lutzoni F, Kauff F, Cox CJ, McLaughlin D, Celio G, et al. (2004) Assembling the fungal tree of life: progress, classification, and evolution of subcellular traits. American Journal of Botany 91: 1446-1480.

Matheny PB, Gossman JA, Zalar P, Arun Kumar TK, Hibbett DS (2006) Resolving the phylogenetic position of the Wallemiomycetes: an enigmatic major lineage of Basidiomycota. Canadian Journal of Botany 84: 1794-1805.

Nagy LG, Ohm RA, Kovács GM, Floudas D, Riley R, et al. (2014) Phylogenomics reveals latent homology behind the convergent evolution of yeast forms. Nature Communications 5: $4471 \mathrm{DOI}$ : 10.1038/ncomms5471.

Nagy LG, Riley R, Tritt A, Adam C, Daum C, et al. (2016) Comparative genomics of early-diverging mushroom-forming fungi provides insights into the origins of lignocellulose decay capabilities. Molecular Biology and Evolution 33: 959-970.

Paps J, Medina-Chacón LA, Marshall W, Suga H, Ruiz-Trillo I (2013) Molecular phylogeny of unikonts: new insights into the position of apusomonads and ancyromonads and the internal relationships of opisthokonts. Protist 164: 2-12.

Powell MJ, Letcher PM, James TY (2017) Ultrastructural characterization of the host-parasite interface between Allomyces anomalus (Blastocladiomycota) and Rozella allomycis (Cryptomycota). Fungal Biology 121: 561-572.

Quandt CA, Beaudet D, Corsaro D, Walochnik J, Michel R, et al. (2017) The genome of an intranuclear parasite, Paramicrosporidium saccamoebae, reveals alternative adaptations to obligate intracellular parasitism. eLife 2017;6:e29594 DOI: 10.7554/ eLife.29594.

Redecker D, Schüßler A (2014) Glomeromycota. In: The Mycota. Vol. VIIA. Systematics and Evolution (McLaughlin DJ, Spatafora JW, eds): 251-269. $2^{\text {nd }}$ edn. Berlin: Springer-Verlag.

Ren R, Sun Y, Zhao Y, Geiser D, Ma H, Zhou X (2016) Phylogenetic resolution of deep eukaryotic and fungal relationships using highly conserved low-copy nuclear genes. Genome Biology and Evolution 8: 2683-2701.

Ren R, Sun Y, Zhao Y, Geiser D, Ma H, Zhou X (2016) Phylogenetic resolution of deep eukaryotic and fungal relationships using highly conserved low-copy nuclear genes. Genome Biology and Evolution 8: 2683-2701.

Riley R, Haridas S, Wolfe KH, Lopes MR, Hittinger CT, et al. (2016) Comparative genomics of biotechnologically important yeasts. Proceedings of the National Academy of Sciences, USA 113: 9882-9887.

Schoch CL, Sung G-H, López-Giráldez FL, Townsend JP, Miadlikowska $\mathrm{J}$, et al. (2009) The Ascomycota tree of life: a phylum-wide phylogeny clarifies the origin and evolution of fundamental reproductive and ecological traits. Systematic Biology 58: 224-239.

Shen XX, Zhou X, Kominek J, Kurtzman CP, Hittinger CT, Rokas A (2016) Reconstructing the backbone of the Saccharomycotina 
yeast phylogeny using genome-scale data. G3: Genes, Genomes, Genetics 6: 3927-3939.

Sherwood-Pike MA, Gray J (1985) Silurian fungal remains: probable records of the class Ascomycetes. Lethaia 18: 1-20.

Spatafora JW, Benny GL, Lazarus K, Smith ME, Berbee ML, et al. (2016) A phylum-level phylogenetic classification of zygomycete fungi based on genome-scale data. Mycologia 108: 1028-1046.

Spatafora JW, Aime MC, Grigoriev IV, Martin F, Stajich JE, Blackwell M (2017) The fungal tree of life: from molecular systematics to genome-scale phylogenies. Microbiology Spectrum 5: FUNK0053-2016doi:10.1128/microbiolspec.FUNK-0053-2016.

Spatafora JW, Johnson D, Sung GH, Hosaka K, O'Rourke B, et al. (2006) A five-gene phylogenetic analysis of the Pezizomycotina. Mycologia 98: 1018-1028.

Sugiyama J, Hosaka K, Suh S-O (2006) Early diverging Ascomycota: phylogenetic divergence and related evolutionary enigmas. Mycologia 98: 998-1007.

Taylor TN, Hass H, Kerp H, Krings M, Hanlin RT (2005) Perithecial ascomycetes from the 400 million year old Rhynie chert: an example of ancestral polymorphism. Mycologia 97: 269-285.

Taylor JW, Berbee ML (2006) Dating divergences in the fungal tree of life: review and new analyses Mycologia 98: 838-849.
Tedersoo L, Sánchez-Ramírez S, Kõljalg U, Bahram M, Döring M, et al. (2018) High-level classification of the Fungi and a tool for evolutionary ecological analyses. Fungal Diversity https://doi. org/10.1007/s13225-018-0401-0

Tehler A (1988) A cladistic outline of the Eumycota. Cladistics 4: 227-277.

Torruella G, De Mendoza A, Grau-Bové X, Antó M, Chaplin MA, et al. (2015) Convergent evolution of lifestyles in close relatives of animals and fungi. Current Biology 25: 2404-2410.

Turland NJ, Wiersema JH, Barrie FR, Greuter W, Hawksworth DL, et al. (eds) (2018) International Code of Nomenclature for algae, fungi, and plants (Shenzhen Code) adopted by the Nineteenth International Botanical Congress Shenzhen, China, July 2017. [Regnum Vegetabile No.159.] Glashütten: Koeltz Botanical Books.

Whittaker RH (1959) On the broad classifications of organisms. Quarterly Review of Biology 34: 210-226.

Zhao RL, Li G-J, Sánchez-Ramírez S, Stata M, Yang Z-L, et al.(2017) A six-gene phylogenetic overview of Basidiomycota and allied phyla with estimated divergence times of higher taxa and a phyloproteomics perspective. Fungal Diversity 84: 43-74. 